\title{
Perforation Rates of Cervical Pedicle Screw Insertion by Disease and Vertebral Level
}

\author{
Masashi Uehara, Jun Takahashi*, Hiroki Hirabayashi, Hiroyuki Hashidate, Nobuhide Ogihara, \\ Keijiro Mukaiyama, Shota Ikegami and Hiroyuki Kato
}

Department of Orthopaedic Surgery, Shinshu University, School of Medicine, 3-1-1 Asahi, Matsumoto-City, Nagano, 390-8621, Japan

\begin{abstract}
Background: Different perforation rates for cervical pedicle screws by disease are expected in relation to bone quality and pedicle morphology; however, no report comparing pedicle screw perforation rate by disease had previously been published. This study investigated the perforation rates of pedicle screws inserted to cervical pedicle by disease and vertebral level using a CT-based navigation system.

Materials/Methods: Fifty-three patients who underwent cervical pedicle screw insertion using CT based navigation system were studied. Diseases included rheumatoid arthritis (RA) (24 cases), destructive spondyloarthropathy (DSA) (10), cervical spondylotic myelopathy (CSM) (9), spine tumor (6), and cervical spondylotic myelopathy associated with athetoid cerebral palsy (CP) (4). Screw perforation rates for cervical pedicle screws were studied. Major perforation was defined as perforation $50 \%$ of screw diameter or more.

Results: Major perforation rate by disease from C3 to C7 was as follows: spine tumor (0/24, 0\%), RA (2/59, 3.4\%), DSA $(3 / 65,4.6 \%)$, CP $(2 / 20,10.0 \%)$, and CSM (6/40, 15.0\%). There were no clinically important complications such as vertebra arterial injury, spinal cord injury, or nerve root injury caused by any screw perforation. Major perforation rate by vertebral level was: $\mathrm{C} 2(2 / 30,6.7 \%), \mathrm{C} 3(4 / 49,8.2 \%), \mathrm{C} 4(6 / 43,14.0 \%), \mathrm{C} 5(1 / 32,3.1 \%), \mathrm{C} 6(1 / 41,2.4 \%)$, and C7(1/45, $2.2 \%$ ), showing highest rate for $\mathrm{C} 4$, followed by $\mathrm{C} 3$.

Conclusions: Cervical pedicle screw perforation rate by disease was higher in CSM compared to RA and DSA. The perforation rate by vertebral level was higher for $\mathrm{C} 4$ and $\mathrm{C} 3$, in this order.
\end{abstract}

Keywords: Cervical pedicle screw, image guidance, perforation rate.

\section{INTRODUCTION}

Cervical spine fixation using cervical pedicle screw (CPS) was first reported by Abumi [1] and Jeanneret [2] in 1994. Both reports described cases of cervical instability caused by cervical trauma. Cervical spine fixation using CPS was introduced as a procedure for the cervical instability of middle and/or lower cervical spine caused by trauma, and the importance of fixation by CPS for posterior cervical decompression and reconstruction was later reported $[3,4]$. Indications for CPS have since been extended, and now include symptoms such as rheumatoid cervical spine, destructive spondyloarthropathy (DSA), and spine tumor [57]. A difference in CPS perforation rate according to bone quality or morphology of pedicle is to be expected; however, whether there are differences in CPS perforation rate due to variation in bone quality because of osteoporosis or osteosclerotic pedicle, or by morphology or size of pedicles, is not clearly understood. In addition, differences in CPS perforation rates according to disease may exist; however, although CPS perforation rates for rheumatoid arthritis (RA), DSA, and trauma treatment by various procedures have been

*Address correspondence to this author at the Department of Orthopaedic Surgery, Shinshu University, School of Medicine, 3-1-1 Asahi, MatsumotoCity, Nagano, 390-8621, Japan; Tel: 81-263-37-2659; Fax: 81-263-35-8844; E-mail: jtaka@shinshu-u.ac.jp reported [8-12], there have been no reports on CPS perforation rates by disease. The purpose of this study is to evaluate the perforation rates of cervical pedicle screw insertion using CT-based navigation system by disease and vertebral level (from $\mathrm{C} 2$ to $\mathrm{C} 7$ ).

\section{MATERIALS AND METHODOLOGY}

Fifty-three patients (27males, 26 females, mean age 64.9 9 9.6years) who underwent cervical pedicle screw insertion using a CT-based navigation system from September 1997 to August 2008 were evaluated. A frameless stereotactic image-guidance system (Stealth Station and Stealth Station TREON ${ }^{\mathrm{TM}}$; Medtronic, Sofamor Danek, Memphis, TN, USA) was used in screw placement and fixation of the cervical spine.

Diseases included 24 cases ( 6 males, 18 females; mean age $65.0 \pm 7.7$ years) of RA, 10 ( 8 males, 2 females; mean age $65.0 \pm 7.2$ years) of DSA, 9 ( 5 males, 4 females; mean age $71.7 \pm 7.4$ years) of cervical spondylotic myelopathy (CSM), 6 (4 males, 2 females; mean age $62.3 \pm 9.1$ years) of spine tumor, and 4 cases $(4$ males; mean age $50.8 \pm 15.9$ years) of cervical spondylotic myelopathy associated with athetoid cerebral palsy $(\mathrm{CP})$. The number of the inserted screws by disease for each pedicle level is shown in Table $\mathbf{1}$. Total 240 cervical pedicle screws from $\mathrm{C} 2$ to $\mathrm{C} 7$ were inserted using CT-based navigation system. 
Table 1. Number of Pedicle Screw Insertions by Pedicle Level

\begin{tabular}{|c|c|c|c|c|c|c|c|}
\hline Disease & C2 & C3 & C4 & C5 & C6 & C7 & Total \\
\hline \hline RA & 17 & 15 & 10 & 5 & 9 & 20 & 76 \\
\hline DSA & 1 & 15 & 16 & 7 & 11 & 16 & 66 \\
\hline CSM & 0 & 11 & 10 & 11 & 8 & 2 & 42 \\
\hline Spine tumor & 8 & 5 & 2 & 4 & 9 & 4 & 32 \\
\hline CP & 4 & 3 & 5 & 5 & 4 & 3 & 24 \\
\hline
\end{tabular}

RA, rheumatoid arthritis; DSA, destructive spondyloarthropathy; CSM, cervical spondylotic myelopathy; CP, cervical spondylotic myelopathy associated with athetoid cerebral palsy.

The procedure used for screw insertion until December 2004 was as follows: an insertion point was confirmed by navi probe, then a screw insertion hole was formed using an air drill. A pedicle probe was used to excavate the screw hole, and then the screw was inserted. The procedure from January 2005 has been as follows: a screw hole is prepared using navigation system with a Kotani probe [8], tapping is performed with a tap that is $0.5 \mathrm{~mm}$ thinner than screw diameter, and the screw is inserted.

All patients underwent reconstruction CT scans (Siemens SOMATOM Sensation 16; Siemens Asahi Meditec Inc., Shinagawa, Tokyo, Japan) of instrumented levels one week after surgery. Pedicle screw perforations of cervical pedicles were evaluated by axial CT images with $1.25 \mathrm{~mm}$ slice thickness. Screw insertion status was classified as follows: grade 1 (no perforation), screw is accurately inserted in pedicle; grade 2 (minor perforation), perforation of less than $50 \%$ of screw diameter; grade 3 (major perforation), perforation of $50 \%$ of screw diameter or more. Perforation rates by disease were compared with Fisher's exact test and Post-hoc test using R, Version 2.6.2, a free open-source statistical analysis system, p-values less than 0.05 were regarded as significant. Furthermore medial and lateral perforations of the pedicle wall were also evaluated.

\section{RESULTS}

Perforation rates from $\mathrm{C} 3$ to $\mathrm{C} 7$ was evaluated by disease because pedicle screw was not inserted for C2 in CSM. Screw perforation rates $(\mathrm{C} 3-\mathrm{C} 7)$ by disease were as follows: perforation rates of grade 3 (major perforation), listed in increasing order, was spine tumor $(0 / 24,0 \%)$, RA $(2 / 59$, $3.4 \%)$, DSA $(3 / 65,4.6 \%)$, CP $(2 / 20,10 \%)$, and CSM $(6 / 40$, $15.0 \%$ ). Rate of grade 3 plus grade 2 , listed in increasing order, was DSA $(5 / 65,7.7 \%)$, RA $(5 / 59,8.5 \%)$, spine tumor $(4 / 24,16.7 \%)$, CP $(6 / 20,30 \%)$, and CSM $(15 / 40,37.5 \%)$ (Table 2). No significant difference was observed for major perforation rates by disease $(\mathrm{p}=0.090)$; however, significant difference was shown in grade $2+3$ perforation rates, including minor perforations $(\mathrm{p}=0.00032)$. Multiple comparison (Post-hoc test) by Ryan method was then performed to see whether the differences between groups had significance, and the differences between CSM and DSA $(\mathrm{p}=0.000070)$ and CSM and RA $(\mathrm{p}=0.00050)$ were significant. CP and spine tumor, of which there were fewer cases, did not show significant difference when compared to DSA or RA. There were no clinically significant complications such as vertebra arterial injury, spinal cord injury, or nerve root injury caused by any screw perforation.

Table 2. Pedicel Screw Perforation Rates from C3 to C7 by Disease

\begin{tabular}{|c|c|c|c|c|c|}
\hline \multirow{2}{*}{ Disease } & \multicolumn{2}{|c|}{ Number of Pedicle Screw } & \multicolumn{2}{c|}{ Perforation Rates (\%) } \\
\cline { 2 - 6 } & Grade 1 & Grade 2 & Grade 3 & Grade 3 & Grade 2+3 \\
\hline \hline RA & 54 & 3 & 2 & 3.4 & 8.5 \\
\hline DSA & 60 & 2 & 3 & 4.6 & 7.7 \\
\hline CSM & 25 & 9 & 6 & 15.0 & 37.5 \\
\hline Spine tumor & 20 & 4 & 0 & 0 & 16.7 \\
\hline CP & 14 & 4 & 2 & 10.0 & 30.0 \\
\hline
\end{tabular}

In addition, results for screws inserted to $\mathrm{C} 3$ to $\mathrm{C} 6$ where insertion was reported as relatively difficult were evaluated. The perforation rates by disease for the pedicle levels from $\mathrm{C} 3$ to $\mathrm{C} 6$, which showed relatively higher perforation rates, were as follows: for grade 3 (major perforation), RA 5.1\%, DSA $6.1 \%$, CSM $15.0 \%$, spine tumor $0 \%$, and CP 5.9\%; and for grade 3 plus grade 2, RA $12.8 \%$, DSA $10.2 \%$, CSM $37.5 \%$, spine tumor $20.0 \%$, and CP $29.4 \%$ (Table 3 ).

Table 3. Pedicel Screw Perforation Rates from C3 to C6 by Disease

\begin{tabular}{|c|c|c|c|c|c|}
\hline \multirow{2}{*}{ Disease } & \multicolumn{2}{|c|}{ Number of Pedicle Screw } & \multicolumn{2}{c|}{ Perforation Rates (\%) } \\
\cline { 2 - 6 } & Grade 1 & Grade 2 & Grade 3 & Grade 3 & Grade 2+3 \\
\hline \hline RA & 34 & 3 & 2 & 5.1 & 12.8 \\
\hline DSA & 44 & 2 & 3 & 6.1 & 10.2 \\
\hline CSM & 25 & 9 & 6 & 15.0 & 37.5 \\
\hline Spine tumor & 16 & 4 & 0 & 0 & 20.0 \\
\hline CP & 12 & 4 & 1 & 5.9 & 29.4 \\
\hline
\end{tabular}

Screw perforation rates by pedicle level were as follows: grade 3 (major perforation), C2(2/30, 6.7\%), C3(4/49, $8.2 \%), \mathrm{C} 4(6 / 43,14.0 \%), \mathrm{C} 5(1 / 32,3.1 \%), \mathrm{C} 6(1 / 41,2.4 \%)$, and $\mathrm{C} 7(1 / 45,2.2 \%)$, showing higher perforation rates for $\mathrm{C} 4$ and $\mathrm{C} 3$. Screw perforation rate by pedicle level for grade 3 plus grade 2 was $\mathrm{C} 2(2 / 30,6.7 \%), \mathrm{C} 3(9 / 49,18.4 \%)$, $\mathrm{C} 4(14 / 43,32.6 \%), \mathrm{C} 5(7 / 32,21.9 \%), \mathrm{C} 6(4 / 41,9.8 \%)$, and $\mathrm{C} 7(2 / 45,4.4 \%)$, showing higher perforation rates for $\mathrm{C} 4, \mathrm{C} 5$, and $\mathrm{C} 3$, in this order (Table 4).

Table 4. Pedicle Screw Perforation Rates by Vertebral Level (\%)

\begin{tabular}{|c|c|c|c|c|c|c|}
\hline & C2 & C3 & C4 & C5 & C6 & C7 \\
\hline \hline Grade 3 & 6.7 & 8.2 & 14.0 & 3.1 & 2.4 & 2.2 \\
\hline Grade 2+3 & 6.7 & 18.4 & 32.6 & 21.9 & 9.8 & 4.4 \\
\hline
\end{tabular}

Numbers of medial and lateral perforations were as follows: Grade 3; 7 and 8 for medial and lateral perforation, 
respectively. Grade 2; 6 and 20 for medial and lateral perforation, respectively. Totals of grades 3 and 2; and 13 and 28 for medial and lateral perforation, respectively, showing that there were twice as many lateral perforations as medial.

Screw perforation numbers by disease were as follows: RA patients, grade $3 ; 0$ and 3 for medial and lateral perforation, respectively. RA patients, grade 2; 0 and 3 for medial and lateral perforation, respectively. Total RA patients; 0 and 6 for medial and lateral perforation, respectively, showing that all the perforations was lateral. DSA patients, grade $3 ; 0$ and 3 for medial and lateral perforation, respectively. DSA patients, grade 2; 0 and 5 for medial and lateral perforation, respectively. Total DSA patients; 0 and 8 for medial and lateral perforation, respectively, showing that all the perforations was lateral. CSM patients, grade $3 ; 5$ and 1 for medial and lateral perforation, respectively. CSM patients, grade 2; 3 and 7 for medial and lateral perforation, respectively. Total CSM patients; 8 and 8 for medial and lateral perforation, respectively, showing the same numbers, though there were more major perforations among the medial perforations. Spine tumor patients, grade 3; 0 for both medial and lateral perforation. Spine tumor patients, grade 2; 2 and 2 for medial and lateral perforation, respectively. Total Spine tumor patients of grade 3 and 2; 2 and 2 for medial and lateral perforation, respectively, showing the same numbers of medial and lateral perforations. CP patients, grade $3 ; 2$ and 1 for medial and lateral perforation, respectively. CP patients, grade $2 ; 1$ and 3 for medial and lateral perforation, respectively. Total CP patients, 3 and 4 for medial and lateral perforation, respectively, showing similar numbers of medial and lateral perforations.

\section{CASE PRESENTATIONS}

\section{Case 1: 68 Year-Old Female with Rheumatoid Cervical Spine}

Pedicle screws were inserted to C6 and C7. Although the pedicles were narrow, pedicle screws were accurately inserted and all screw insertions were of grade 1 (Fig. 1).

\section{Case 2: 71 Year-Old Female with CSM}

Pedicle screws were inserted to bilateral $\mathrm{C} 3$ and $\mathrm{C} 5$. Although pedicles were not narrow, right $\mathrm{C} 3$ and $\mathrm{C} 5$ pedicle screws were completely perforated (grade 3 ) to medial side (Fig. 2).

\section{DISCUSSION}

Cervical pedicle screws can achieve rigid fixation compared to other cervical pedicle fixation methods $[13,14]$, and enable posterior cervical pedicle decompression. However, cervical pedicle screw insertion is technically demanding because of the narrow pedicle diameter and the risk of serious neurovascular complications including vertebral artery tear, spinal cord injury, and nerve root injury [15]. Indication of cervical pedicle screw technique is as follows: destructive lesions including RA, DSA, and spine tumor; procedures that include both spinal cord decompression and posterior fusion. For rheumatoid cervical spine, this technique is especially useful because the strong initial fixation eliminates the necessity of postoperative external fixation such as halo vest or neck collar.

To achieve more accurate and safe pedicle screw insertion, navigation by two-dimensional imaging system or CT has been employed in recent years. In the meta-analysis reported by Tian et al. the accuracy of pedicle screw insertion by CT navigation $(90.76 \%)$ was significantly improved compared to the two-dimensional imaging system (85.48\%) [16]. Our institution employs a CT-based navigation system for the cervical pedicle screw insertion [9].

Among the previous reports of perforation rates of cervical pedicle screw by disease, the perforation rates for RA, DSA, and spinal trauma were 0-22\% [9,10], 6.1\% [11], and $3.9-9.2 \%$ [12], respectively. Insertion methods employed in these reports included CT-based navigation and twodimensional imaging systems. However, there was no report that compared pedicle screw perforation rate by disease, and therefore we reported pedicle screw perforation rate by disease in the present study. Results of screw insertion
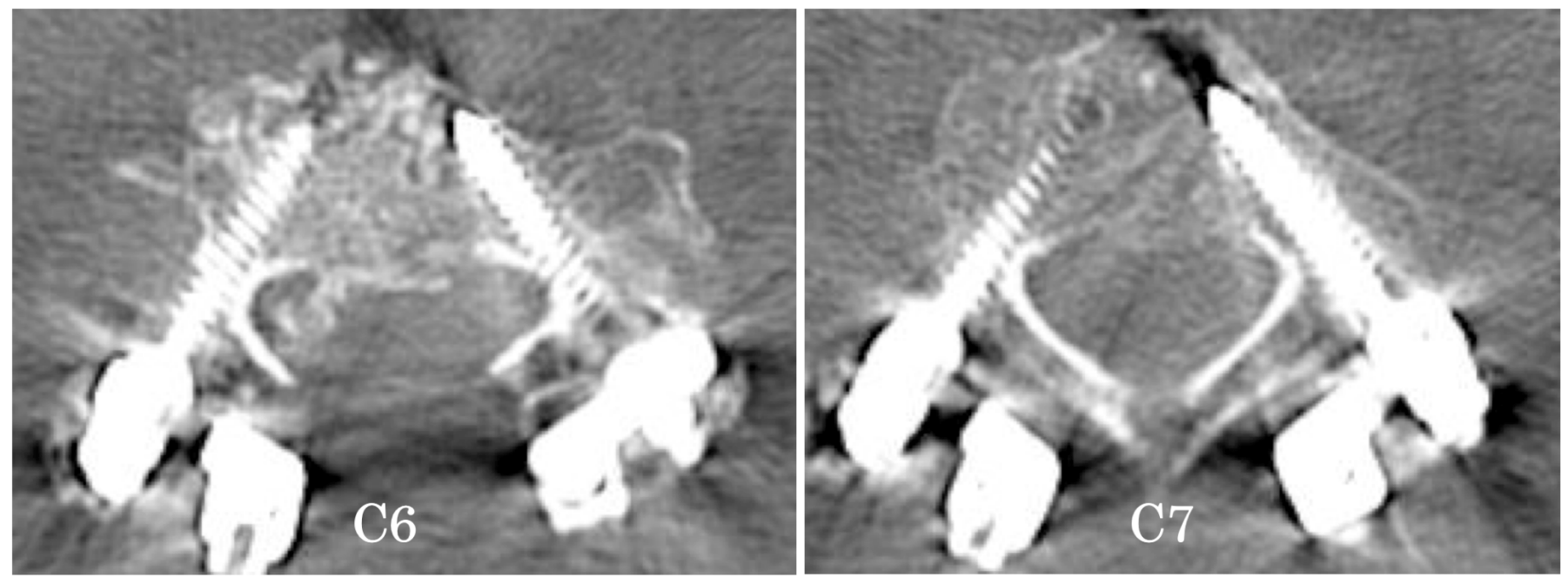

Fig. (1). 68 year-old female with rheumatoid cervical spine. Pedicle screws were inserted to C6 and C7, and all screws were of grade 1 (no perforation). 

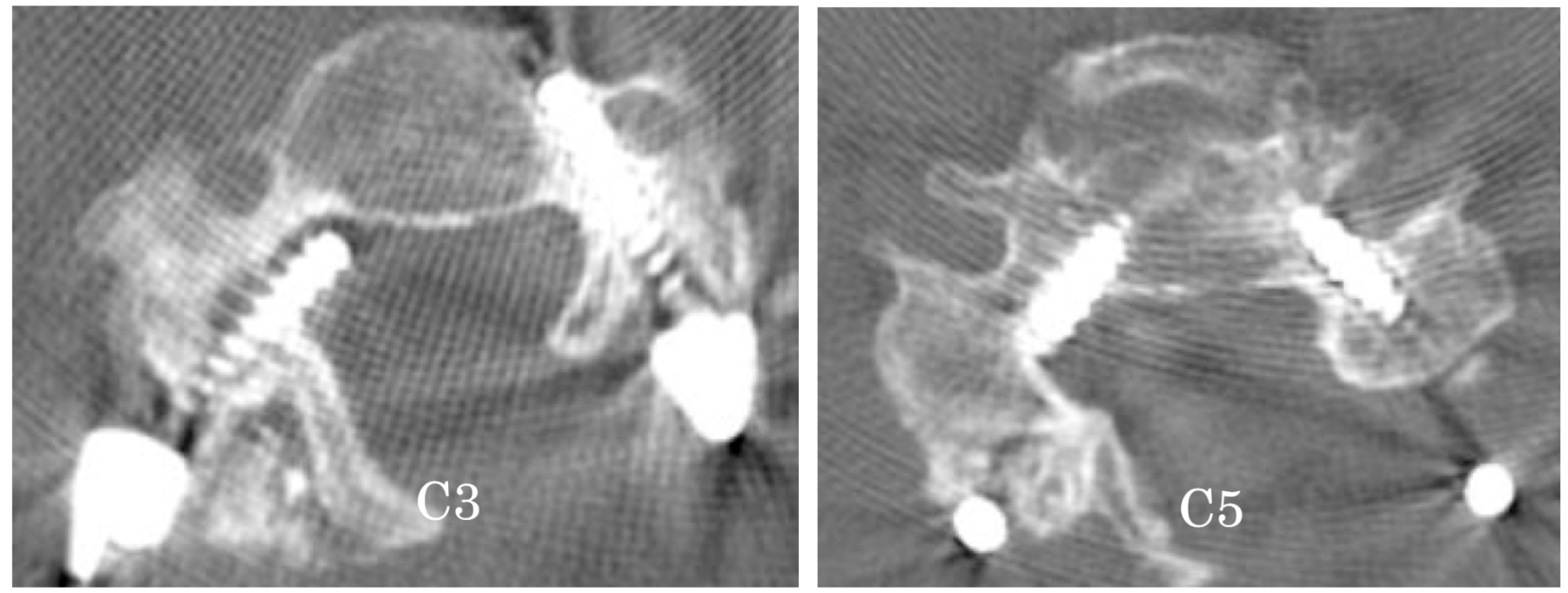

Fig. (2). 71 year-old female with cervical spondylotic myelopathy. Pedicle screws were inserted to bilateral C3 and C5. Right C3 and C5 were completely perforated to medial side, and were of grade 3 (major perforation).

analysis showed relatively low perforation rates for spine tumor, RA, and DSA, but higher rates for CSM and CP. These results lead us to speculate that the low perforation of spine tumor resulted from relatively wider pedicle because of low average age (62.3 year-old), smaller spinal degeneration, and normal structure.

RA and DSA cases that showed relatively low perforation rates were reportedly associated with higher incident of osteoporosis and lower BMD [17, 18]. RA shows higher tendency to present osteoporosis because of secondary osteoporosis caused by steroid treatment. In summary, though RA and DSA patients showed narrower pedicles, they presented soft bone quality and probe insertion was easy, thus bone cortex was not easily perforated. For $\mathrm{CSM}$ and $\mathrm{CP}$, strong deformity was observed and sometimes pedicle became osteosclerotic, thus the probe could not be easily inserted, resulting in perforation. When pedicles are osteosclerotic and a Kotani probe [8] can not be inserted, direction is decided by navi probe, the insertion point is prepared by speed drill, and the pathway of screw is made by a pedicle probe with sharp tip. Pedicle holes are prepared by speed drill or hitting the pedicle probe with a hammer, and during this procedure bone cortex could be broken. Osseous hardness has a great influence on the direction of screw insertion as far as manual handling, even if navigation system is used.

The screw perforation direction showed twice as many lateral perforations compared to medial perforation. All the cases of RA and DSA with osteoporosis showed lateral perforation. In contrast, the cases of CSM and CP with osteosclerotic condition showed almost the same numbers of medial and lateral perforations. These results were presumably caused by the differences in bone quality by disease. In conclusion, attention should be paid for lateral perforation in RA and DSA and for both lateral and medial perforation in CSM and CP.

The possible causes of perforation of pedicle screw are as follows: Deviation of CT-based navigation system caused from unintentional movement of reference flame during operation etc. lateral perforation caused by pressure from paravertebral muscle to Kotani probe, tap, or screw; narrow osteosclerotic pedicle that has no cancerous bone. To avoid perforation under such conditions, countermeasures as follows are required: If the practitioner judges the insertion point or screw direction shown by the navigation system is incorrect, intraoperative X-Ray image or fluoroscopy shall be used. If screw direction could not be set sufficiently in the medial orientation, prepare a skin incision externally and insert Kotani probe, tap, and screw from the incision. In the case of narrow or osteosclerotic pedicle, skip the pedicle or change the fixation method to lateral mass screw, sublaminar cable, or other.

For perforation rate by vertebral level, $\mathrm{C} 3$ and $\mathrm{C} 4$ showed higher perforation rates. Kayalioglu et al. [19] reported that pedicle diameter is the narrowest for $\mathrm{C} 3$ and gradually becomes wider to C6. Onibokun et al. [20] reported wider pedicle transverse angle from $\mathrm{C} 3$ to $\mathrm{C} 6$ compared to $\mathrm{C} 7$. Thus, higher perforation rates would occur to narrower pedicles, and pressure caused by paravertebral muscle usually pushes the screws medially and the decreased insertion angle causes lateral perforation. Thus, to avoid perforation, countermeasures, including making an additional skin incision laterally, should be performed. We generally employ polyaxial screws of $3.5 \mathrm{~mm}$ diameter from $\mathrm{C} 3$ to $\mathrm{C} 6$, and $4.0 \mathrm{~mm}$ screw for rescue. For $\mathrm{C} 2$ and $\mathrm{C} 7$, which generally have wide pedicles, $4.0 \mathrm{~mm}$ polyaxial screws are sometimes employed. This study revealed that $\mathrm{C} 3$ and $\mathrm{C} 4$ have higher perforation rates, and to improve the accuracy of surgery, use of the lateral mass screw could be better for $\mathrm{C} 3$ and $\mathrm{C} 4$ levels.

Regarding the number of screw insertions by vertebral level and disease, a larger number of CPSs was inserted to the following: $\mathrm{C} 4$ and $\mathrm{C} 5$ for $\mathrm{CP} ; \mathrm{C} 3, \mathrm{C} 4$, and $\mathrm{C} 5$ for $\mathrm{CSM}$; and $\mathrm{C} 2$ and $\mathrm{C} 7$ for RA. There was concern that these screw insertion positions might affect the results of this study. To clarify this question, we evaluated the perforation rates for the vertebral levels from $\mathrm{C} 3$ to $\mathrm{C} 6$ where CPS insertion was difficult and higher perforation rate was observed. Results showed lower CPS perforation rates for DSA and RA compared to CSM and $\mathrm{CP}$, showing consistent results. 


\section{CONCLUSION}

Cervical pedicle screw perforations rate by disease was higher in CSM compared to RA and DSA. The perforation rates by vertebral level was higher for $\mathrm{C} 4$ and $\mathrm{C} 3$, in this order.

\section{REFERENCES}

[1] Abumi K, Itoh H, Taneichi H, Kaneda K. Transpedicular screw fixation for traumatic lesions of the middle and lower cervical spine: Description of the techniques and preliminary report. J Spinal Disord 1994; 7: 19-28.

[2] Janneret B, Gebhard JS, Magerl F. Transpedicular screw fixation of articular mass fracture separation: Results of an anatomical study and operative technique. J Spinal Disord 1994; 7: 222-9.

[3] Abumi K, Kaneda K. Pedicle screw fixation for nontraumatic lesions of the spine. Spine 1997; 22: 1853-63.

[4] Abumi K, Kaneda K, Shono Y, Fujiyama M. One-stage posterior decompression and reconstruction of the cervical spine by using pedicle screw fixation systems. J Neurosurg 1999; 90: 19-26.

[5] Ludwig SC, Kramer DL, Vaccaro AR, Albert TJ. Transpedicular screw fixation of the cervical spine. Clin Orthop Relat Res 1999; 359: 77-88.

[6] Ebraheim NA, Xu R, Knight T, Yeasting RA. Morphometric evaluation of lower cervical pedicle and its projection. Spine 1997; 22: 1-5.

[7] Panjabi MM, Shin EK, Chen NC, Wang JL. Internal morphology of human cervical pedicles. Spine 2000; 25: 1197-205.

[8] Kotani Y, Abumi K, Ito M, Minami A. Improved accuracy of computer-assisted cervical pedicle screw insertion. J Neurosurg 2003; 99(3 Suppl): 257-63.

[9] Takahashi J, Shono Y, Nakamura I, et al. Computer-assisted screw insertion for cervical disorders in rheumatoid arthritis. Eur Spine J 2007; 16: 485-94.

[10] Ito $\mathrm{H}$, Neo M, Yoshida M, et al. Efficacy of computer-assisted pedicle screw insertion for cervical instability in RA patients. Rheumatol Int 2007; 27(6): 567-74.
[11] Yuzawa Y, Kamimura M, Nakagawa H, et al. Surgical treatment with instrumen- tation for severely destructive spondyloarthropathy of cervical spine. J Spinal Disord Tech 2005; 18(1): 23-8.

[12] Yukawa Y, Kato F, Ito K, et al. Placement and complications of cervical pedicle screws in 144 cervical trauma patients using pedicle axis view techniques by fluoroscope. Eur Spine J 2009; 18(9): 1293-9.

[13] Jones EI, Heller JG, Silcox DH, Hutton WC. Cervical pedicle screws versus lateral mass screws: Anatomic feasibility and biomechanical comparison. Spine 1997; 22: 977-82.

[14] Kotani Y, Cunningham BW, Abumi K, McAfee PC. Biomechanical analysis of cervical stabilization systems: An assessment of transpedicular screw fixation in the cervical spine. Spine 1994; 19: 2529-39.

[15] Karaikovic EE, Kunakornsawat S, Daubs MD, Madsen TW, Gaines RW Jr. Surgical anatomy of the cervical pedicles: Landmarks for posterior cervical pedicle entrance localization. J Spinal Disord 2000; 13: 63-72.

[16] Tian NF, Xu HZ. Image-guided pedicle screw insertion accuracy: A meta-analysis. Int Orthop 2009; 33(4): 895-903.

[17] Başkan BM, Sivas F, Alemdaroğlu E, Duran S, Ozoran K. Association of bone mineral density and vertebral deformity in patients with rheumatoid arthritis. Rheumatol Int 2007; 27(6): 57984.

[18] Yamamoto T, Matsuyama Y, Tsuji T, et al. Destructive spondyloarthropathy in hemodialysis patients: Comparison between patients with and those without destructive spondyloarthropathy. J Spinal Disord Tech 2005; 18(3): 283-5.

[19] Gulgun Kayalioglu, Meta Erturk, Tuncay Varol, Cezayirli E. Morphometry of the cervical vertebral pedicles as a guide for transpedicular screw fixation. Neurol Med Chir (Tokyo) 2007; 47: 102-7.

[20] Onibokun A, Khoo LT, Bistazzoni S, Chen NF, Sassi M. Anatomical conciderations for cervical pedicle screw insertion: the use of multiplanar computerized tomography measurements in 122 consecutive clinical cases. Spine J 2009; 9(9): 729-34. 